\title{
FORMAÇÃO CRÍTICA DE PROFESSORES DE LÍNGUAS: UMA PROPOSTA EMANCIPATÓRIA E POLÍTICA
}

Hélvio Frank de Oliveira é Doutor em Letras e Linguística pela Universidade Federal de Goiás, professor efetivo na Universidade Estadual de Goiás, onde atua na área de formação de professores de línguas do Departamento de Letras (Português/Inglês) e no MIELT - Mestrado Interdisciplinar em Educação, Linguagem e Tecnologias. Também é professor colaborador no Programa de PósGraduação em Linguística Aplicada da Universidade de Brasília, onde ministra disciplinas e orienta dissertações de Mestrado.

E-mail: helviofrank@hotmail.com

\section{Resumo}

O objetivo deste estudo é analisar o impacto de um curso de reflexão crítica ministrado na formação inicial de professores de línguas de uma universidade estadual pública de Goiás a partir da voz de oito licenciandos participantes. Trata-se de uma pesquisa qualitativa pautada pelos pressupostos da pesquisa-ação crítico-colaborativa cujo método envolve os conceitos de reflexão crítica e colaborativa na formação de professores de línguas.

Inúmeros estudos na área de formação de professores de línguas já detectaram lacunas e incompletudes na formação inicial e profissional de docentes (GIL; VIEIRAABRAHÃO, 2008; GIMENEZ, 2004; LIBERALI, 2010). Essas pesquisas constataram, entre outros resultados, que é comum passarmos por um curso de formação inicial e, no espaço de quatro anos, fazer parte da rotina formadora de modelos sobre como "ensinar" línguas. Por meio de instruções fortemente influenciadas por uma visão de formação intitulada por Mateus (2010, p. 28) de "racional-técnico-utilitarista", parecem não faltar métodos, metodologias e técnicas, bem como práticas e modelos sobre como se portar diante da ação de ensinar línguas.

No processo tradicional ainda bastante arraigado em alguns cursos de licenciatura em Letras, especialmente endereçados à área de inglês como língua estrangeira (doravante ILE), os futuros teachers, por meio de ações bastante verticalizadas, recebem fórmulas ajustadas de ensinar o idioma por parte de seus professores formadores. Entretanto, pesquisas recentes no âmbito da Linguística Aplicada Crítica (LAC) têm buscado questionar, de forma contundente e crítica, essa única prática como foco de determinados processos de ensino-aprendizagem e de formação de professores de línguas (HAWKINGS; NORTON, 2009; MATEUS; OLIVEIRA, 2014; MOITA LOPES, 2003, 2006; PENNYCOOK, 1999, 2004).

Em seus fundamentos gerais, as teorizações provenientes desses trabalhos têm evidenciado a importância de se pensar a complexidade existente em sala de aula como espaço de negociação de artefatos sociais, culturais, ideológicos, econômicos, entre outras representações hierárquicas e/ou historicamente construídas no pano contextual das relações de poder, envolvendo as práticas discursivas de heterogêneos agentes diretos e indiretos dos processos de ensinar e aprender.

Nesse caminho, pautada na essencialidade da crítica, a proposta deste artigo é caracterizar, por meio de narrativas dos cursistas participantes de um curso de reflexão crítica instaurado durante a graduação em Letras, como essa iniciativa pôde contribuir para a (trans)formação inicial de futuros professores, com vistas à produção de 
conhecimentos de mundo e linguísticos, à formação questionadora e crítica das situações e condições de ensino e da prática docente para além da língua. Para isso, discuto, nas próximas seções, a necessidade de formar professores críticos para um ensino de línguas que ultrapasse a dimensão da racionalidade técnica, o papel do discurso nas práticas educacionais e a relevância de se problematizar tais práticas que envolvem relações de poder em sala de aula de língua estrangeira (LE). Se, de acordo com Moita Lopes (2003, p. 31), "não se pode transformar o que não se entende", acredito que as próximas linhas, ainda que incipientes, buscarão desvelar e desvendar as referidas questões pedagógicas, a fim de uma compreensão seguida, espero, de atitudes encorajadoras que propiciem a mudança de professores de línguas.

\section{1) A formação de professores para além do ensino de línguas}

Vários estudos na área de Linguística Aplicada apontaram para a necessidade de (re)pensar a formação do professor de línguas num processo de transformação com vistas a adequar a uma proposta além da língua, a qual conceba o espaço sala de aula como mundo social em que os discursos que ali circulam correspondem a representações da realidade construída durante as negociações imbuídas no ato de ensinar (MOITA LOPES, 2003; PENNYCOOK, 2004; URZEDA-FREITAS; PESSOA, 2014). Em sua maioria, esses autores concordam sobre a relevância de se educar profissionais para ensinar línguas, de modo a exceder com componentes meramente gramaticais e vocabulares do idioma, e avançar no sentido de contribuir para uma visão de formação emancipatória e política dos envolvidos nessas relações sociais. Está claro que, ao ensinar o verbo to be, estão em jogo muito mais eventos socioculturais, complexos e dinâmicos, do que meramente a técnica ou o método efetivado para transmitir o insumo linguístico - oral e/ou escrito - ao aluno da escola.

Pensada à luz de uma dimensão política, a formação docente passa a conceber a vida real dos indivíduos inserida nas práticas sociais e caracterizada pela representação de discursos que envolvem relações de poder, escolhas e posicionamentos que, por sua vez, têm impactos diferenciados em dado contexto de interação social e nele interferem de variadas formas. Daí a importância de se formar profissionais docentes críticos, éticos, tendo em vista o contexto social em que o ensino é desenvolvido, conforme sublinham Borelli e Pessoa (2011) e Oliveira (2013).

De tal forma a transgredir o ensino pautado por rigores metodológicos, a perspectiva de formação além da língua, grosso modo, visa a conduzir professores e alunos a uma reflexão sobre suas práticas direcionadas a uma linha crítica e, a partir disso, reconstruir ou desconstruir todo o tipo de conhecimento fixo, pronto ou definido em termos de condições sociais e/ou processos de ensino aprendizagem perpassados histórico e culturalmente como corretos. Conforme indicam Urzeda-Freitas e Pessoa (2014), as relações de sala de aula não correspondem a ensaios da vida, ou, pelo menos, não o deveriam ser. $\mathrm{Na}$ realidade, conforme salientam, significam a própria vida acontecendo. 
Sob essa ótica, asseveram Borelli e Pessoa (2011), valores como a verdade, por exemplo, tornam-se dignos de questionamento, assim como as relações de poder que subjazem essas representações e/ou contribuem para sua manutenção. Automaticamente, o professor - ou mesmo os alunos - dotado de uma visão crítica, pode fazer leituras que ultrapassem os limites desses acontecimentos de sala de aula que, muitas vezes, configuram-se como colaboradores de práticas hegemônicas operantes nesse ambiente.

Se a formação considera que estudantes, ao buscarem aprender ILE, aliam esse interesse cognitivo a razões sociais e pessoais, o que significa dizer que existem expectativas próprias acerca do que eles farão com essa nova língua aprendida no mundo social (BARCELOS, 2004), de igual modo, convém direcionar esse processo para a valorização e exploração de contextos em que o uso real da língua seja fielmente propiciado.

Rajagopalan (2001) afirma que aprender línguas é redefinir identidades. Nesse sentido, não adianta mais fingir ser o John ou a Mary, e simular um diálogo artificial proposto pelo livro didático para aprender ILE. Nos arranjos sociais da vida real, não é possível o indivíduo desvincular-se de si próprio e assumir outras identidades com as quais não se identifica ou das quais não compartilha na hora de construir o conhecimento e/ou de se relacionar socialmente por meio da aprendizagem, da língua. Principalmente, porque língua e subjetividade são produzidas de forma imbricada e, unidas, nos fazem tornar únicos a cada circunstância.

Nesse bojo, ensinar/aprender caracteriza-se, por tabela, como um processo dinâmico e dialógico, promovido por espaços de negociação fluídos pelo discurso das mais variadas intenções, de maneira a movimentar identidades. Nesse caso, a formação de agentes transformadores necessitará de ingredientes adicionais, para que aspectos técnicos e didáticos sejam bem sucedidos e os alunos, de fato, aprendam e, por ora, utilizem tais conhecimentos apreendidos para modificar suas vidas, suas histórias, quando isso se fizer necessário.

Por essas mesmas circunstâncias, a formação de professores sob a perspectiva emancipatória necessita (re)pensar o papel de ensinar desempenhado no ambiente escolar, que se torna um recorte micro da sociedade macro. Nesse cenário, (co)existem alunos - cidadãos - aprendendo língua para usá-la e, por consequência, estejam sendo educados para a vida por meio desse mesmo instrumento de aprendizagem. Por isso, deve ser prevista a existência de dimensões políticas nas atividades de ensino estabelecidas pelo professor, as quais, por meio do discurso, podem influenciar e/ou modificar realidades.

Vivemos em uma sociedade composta de indivíduos heterogêneos, contraditórios, híbridos, imersos nas condições capitalistas neoliberais balizadas pela globalização e era tecnológica. Diante desses novos e incertos modos de vida, a formação de professores para a contemporaneidade necessita exceder fundamentos da racionalidade técnica e a doutrina exclusiva dos métodos. Isso não significa retirar a reflexão sobre os métodos da proposta de formação, mas, sobretudo, propor-lhes a crítica ao serem suplementados por outros processos, alguns dos quais pretendo esboçar 
aqui e que qualificam a boa formação de um professor de línguas, agente social e político, presente e atuante no mundo.

\section{2) O discurso no ensino de línguas}

Bakhtin (2004) afirma que a linguagem consiste em um fenômeno intensamente social, histórico e ideológico no/pelo qual o sujeito se constitui, a partir de relações discursivas instauradas pela dialogia entre o eu e o(s) outro(s). Trazendo esse conceito para a sala de aula, é possível observar que, nesse espaço social, há, durante todo o tempo, negociação de significados, a qual atinge movimentos complexos e importantes de serem refletidos durante a formação de professores que ensinam línguas (JOHNSON, 2009).

Cabe destacar que a relevância do discurso só pôde ser orientada a partir da ampliação dos conceitos inerentes à língua, que, por sua vez, deixou de ser vista apenas como mero instrumento de comunicação, passando a assumir uma acepção mais abundante. Então, nessa visão mais contemporânea, a linguagem passa a ser concebida como forma de interação e como elemento constitutivo do conhecimento humano produzido socialmente (VYGOTSKY, 1998). O homem fala do mundo por meio da língua que, por sua vez, é tida como expressão de seu pensamento e de sua cultura (SAPIR, 1949), e acrescentando-lhe um viés discursivo, refere-se a um instrumento de comunicação imbuído de ideologias, intenções, entre outros elementos.

Diante desse conjunto, torna-se essencial observar a língua de um aluno acoplada de forma tênue à sua cultura, pensamento, discurso. Ao mesmo tempo, concebe-se que é por meio dessas mesmas dimensões que a figura social e política do professor atua, uma vez que, em sala de aula, esse agente reverbera discursos durante suas exposições de ensino, na mesma proporção em que os alunos o fazem diante da aprendizagem. Muitas vezes, é claro, isso ocorre sem que alunos e professor tenham plena consciência dessas práticas discursivas que envolvem elementos complexos como as relações de poder.

Ao incrementar a noção de discurso para este texto, longe de conceituá-lo segundo as dimensões que ele realmente ocupa e pelas quais é caracterizado teoricamente, busco, de forma bastante simplista e crítica, apenas agrupá-lo à concepção de língua e de linguagem, que são processos igualmente diferenciados. Nesse sentido, o discurso atinge suma importância no universo e nas esferas social, cultural, política, ideológica, entre outras, por meio de produção e efeito de significados linguísticos produzidos no ambiente de sala de aula (FAIRCLOUGH, 2001).

Pensado nesse caminho, o discurso permeia a constituição e a construção do homem por meio de processos dialógicos, de um ser que se relaciona com o outro (BAKHTIN, 2004) e se estende à dimensão das relações de poder (FOUCAULT, 1993). Nessa perspectiva, passa a ser compreendido além de sua natureza simbólica e representativa de mundo, e atinge sua natureza sócio-construcionista e constitutiva, de maneira a configura-se, sobretudo, como o lugar privilegiado de manifestação de ideologias, entre outros valores sociais, conforme sugere Moita Lopes (2003). Talvez, 
por essa razão, o autor em questão afirma que a educação linguística esteja no centro da vida contemporânea, uma vez que o discurso ocupa um papel preponderante na vida social e, ecoando Santos (2000, p. 74), porque o homem vive em "um mundo no qual nada se faz sem discurso". Daí a importância de o professor de línguas preocupar-se com questões relativas à natureza sociopolítica dos processos de ensino-aprendizagem de línguas, tendo em vista que a situcionalidade da educação linguística concentra-se no mundo social e, dessa forma, há dois caminhos a serem percorridos por professores de ILE:

ou colaboram com sua própria marginalização ao se entenderem como 'professores de línguas' sem nenhuma conexão com questões políticas e sociais [...], ou percebem que, tendo em vista o fato de trabalharem com linguagem, estão centralmente envolvidos com a vida política e social. (MOITA LOPES, 2003, p. 33)

Como é possível observar, podem ser inúmeras as contribuições provenientes de professores de línguas por meio da centralidade do discurso. Como estudiosos da língua, esses docentes possuem uma ferramenta com força potencial para construir, desconstruir e/ou reconstruir o mundo social, as pessoas e a si próprios, bastando apenas a ação por intermédio desse instrumento de comunicação. Aliás, convém acrescentar, é por meio da reflexão sobre o discurso que compreendemos onde estão situadas nossas ações pedagógicas, onde estão depositadas nossas crenças, de onde nos posicionamos e/ou situamos para falar, para agir de determinada forma. Mais ainda, apreendemos significados de construção da aprendizagem em sala de aula ao observar como esses discursos são construídos em/sobre a língua alvo, enfim, crescemos em vida e em língua e, de fato, nos formamos.

Com efeito, o discurso, em contextos de sala de aula, torna-se um recurso para o professor de línguas com uma boa formação. Se o professor ensina com criticismo e reflexão, suas aulas consequentemente delineiam aspectos de uma prática cuja visão e conteúdos aplicados tornam-se democráticos e legitimadores e, consequentemente, seus alunos passam a ser avaliadores e críticos das condições sociais, econômicas etc. que lhes são postas (BORELLI; PESSOA, 2011). Todo professor - e não necessariamente apenas o de línguas - deveria refletir sobre ações e posições sociais que lhe são postas e avaliar as condições pelas quais seus alunos e suas abordagens são mediados. Por ser um cidadão com uma história e uma missão social em sala de aula, o docente se conecta ao mundo sob uma agenda política, da qual ele não pode desvencilhar-se, para agir diretamente com a problematização dos discursos.

\section{3) Problematização de práticas}

Muitos dos problemas existentes, hoje, em sala de aula de ILE tiveram origem no discurso situacionalmente contextualizado. Sabemos, pois, que ideologias, crenças, representações, discursos não nascem com as pessoas, são valores perpassados de maneira social, histórica e (re)construídos nas práticas sociais que envolvem relações de poder. Por isso, da mesma forma, esses produtos sociais surgidos das relações humanas 
podem ser elementos passíveis de problematização e de crítica no processo de ensino e de formação docente (OLIVEIRA, 2013). Refletir e agir sobre esses discursos em sala de aula torna-se uma proposta desafiadora de ensino além da língua, uma vez que, quando (in)conscientemente ignorados pelo professor, uma gama de intersecções tais como preconceitos, ideologias, vozes silenciadas por intermédio deles se instala. Ao mesmo tempo, é relevante repensar na ação de silenciar os alunos pela qual o professor opta na tentativa de amenizar as tensões surgidas nas relações sociais de conflito. Abafar os discursos discentes buscando neutralizar as tensões e o clima de sala de aula, para prosseguir tranquilamente com a aula, pode reverberar outras manifestações de sentido discentes no presente e no futuro.

Contreras (2002, p. 185), a esse respeito, enfatiza a necessidade de o professor "desentranhar a origem histórica e social do que se apresenta como 'natural', para captar e mostrar os processos pelos quais a prática de ensino fica presa em pretensões, relações e experiências de duvidoso valor educativo". Por isso, nessas horas, ao invés de esmaecer os discursos, deveria haver problematizações e concessões de turnos aos alunos. Mais ainda, a chamada para a discussão após o conflito deveria ser tema da aula de ILE naquele instante, porque, como afirma Moita Lopes (2003), em situações de sala de aula, é prevista a existência de relações de poder institucionalizadas e caracterizadas por marcações sociais envolvendo gênero, raça, cor, religião, posição, status social e econômico, entre outros aspectos presentes nas interações rotineiras do ambiente escolar.

Todos esses fatos e fatores, à medida que visitam a construção da aprendizagem e negociação de significados dos alunos em sala de aula, podem ocupar lugar especial na aula de ILE. Eles podem, conforme indicam Urzeda-Freitas e Pessoa (2014), configurar-se como conteúdos de ensino, por meio de problematizações, questionamentos, observando o que os alunos têm a falar. $\mathrm{O}$ resultado obtido quando o ensino crítico de ILE foi utilizado como dispositivo para a aprendizagem no estudo desses autores consistiu em ampliação de vocabulário no idioma, despreocupação com monitorar a estrutura sintática desenvolvida na oralidade e na argumentação e o que, a meu ver, tornou-se o maior lucro: a contribuição crítica para a percepção da existência da diversidade, da diferença e a promulgação do respeito, o qual não significa aceitação, mas envolve conscientização.

A partir do momento em que a crítica é instaurada e, consequentemente, temos nosso ensino para além da língua, conseguimos refletir, entender e transcender a construção e constituição do espaço de sala de aula, bem como os discursos que sobre e que nela rondam. Se a sala de aula passa a ser observada como espaço social em que existem práticas discursivas movimentadas por relações de poder entre os sujeitos, ela não pode mais ser pensada como um lugar idealizado de transação pedagógica neutra, constituída por um cenário onde professor ensina e alunos aprendem "bonitinhos, sentadinhos". Com isso, começamos a compreender a infinitude de processos discursivos que circundam esse ambiente de relações humanas e passamos a questionar determinadas verdades e posturas, analisar o porquê de alguns alunos falarem mais do que outros, observar, durante as interações, pistas que denunciam o porquê de 
determinadas ações discentes, e, ainda, a notar um pano de relações sociais/hierarquias que sufocam as minorias presentes em sala de aula, as "vozes do sul" (MOITA LOPES, 2006), marginalizadas e, no entanto, a compor fisicamente o espaço destinado à aprendizagem.

Se, como descreve Austin (1965), por meio dos elementos da língua, agimos sobre o mundo, e as formas linguísticas que adotamos não podem ser tidas como meras descrições da realidade, mas antes como um fazer, logo, na condição de professores, podemos transformar a língua-alvo no foco a ser construído por meio dessa aprendizagem, o que seria a verdadeira educação. Isso ocorre porque a língua se torna um ato que altera a realidade do mundo e das pessoas engajadas em tal ação.

Contemplado por esses domínios, o professor pode se valer de seu ato de fala para problematizar aspectos do ensino e do próprio conteúdo apresentado e negociado com os alunos. Pode, sobretudo, fazer com que a língua ensinada se transforme em um objeto discursivo cada vez mais concreto nas práticas escolares e de maneira a transcender seu nível metalinguístico proposto por estruturas fonológica, morfológica e sintática que, ao máximo, serão pensadas em condições de produção e circulação, e alcançarão dimensões semânticas e pragmáticas, vinculadas exclusivamente à materialidade linguística.

Urzeda Freitas e Pessoa (2014) sinalizam que assuntos críticos podem ser debatidos em aula de ILE. Suas teorizações acerca de experiências com assuntos polêmicos e críticos tratados nas aulas ocasionaram a reflexão, a emancipação, aguçaram a crítica e produziram alunos pensantes diante dos temas propostos na vida real. Dessa forma, os autores entendem que é possível buscar o verdadeiro ensino de línguas que ultrapasse aspectos puramente inerentes ao idioma, acelere a compreensão de mundo, sob forma de emancipação e desencadeie novas formas de ação.

A meu ver, todo professor, todo aluno, todo cidadão precisa entender o mundo em que vive e, portanto, os processos sociais, políticos, econômicos, históricos, ideológicos e culturais que vivencia. Nesse contexto, os discursos construídos na língua alvo podem fazer parte do ensinar além da língua e, ao mesmo tempo, garantir insumo no idioma e na vida social. Se, nas palavras de Freire, a educação liberta, nós podemos incentivá-la em aulas de línguas. Só assim "a educação problematizadora, de caráter autenticamente reflexivo, implica[rá] um constante ato de desvelamento da realidade" (FREIRE, 2006, p. 80).

\section{4) Metodologia}

Este estudo, de caráter qualitativo, é pautado pelos pressupostos de uma pesquisa-ação crítico-colaborativa, conforme sugere Pimenta (2006), e foi desenvolvida durante um semestre de curso de Reflexão Crítica implantado na licenciatura em Letras como parte de um projeto de pesquisa, e conduzido com oito alunos voluntários do último ano. Sob o caráter extracurricular e colaborativo, foi ministrado por mim, professor formador e pesquisador, e teve a duração de sessenta horas, divididas em quinze encontros semanais de quatro horas cada. 
Os encontros foram bastante variados e se caracterizaram por: leitura prévia e discussão de teorias lidas e, com o avanço dos encontros, da produção das seguintes tarefas práticas propostas: apresentação e problematização de conteúdos insuficientes ou preconceituosos propostos por livros didáticos, produção de narrativas multimídia sobre experiências críticas de ensinar durante o Estágio docente obrigatório, análise de vídeo de alguns eventos críticos ocorridos - gravados durante a própria regência em escolas públicas de ensino médio -, mediante autorização dos envolvidos, elaboração e defesa de projetos críticos de intervenção no contexto, depoimentos e sentimentos sobre o curso desenvolvido. Os instrumentos de pesquisa utilizados para coletar os dados ao longo das etapas foram notas de campo, questionários abertos, gravação em aúdio, sessões reflexivas individuais e entrevista semiestruturada coletiva. Como procedimento de análise de dados, foi utilizado o critério de agrupamento por recorrência temática dos discursos produzidos a partir das respostas e afirmações apresentadas pelos participantes em alinhamento ao objetivo delineado neste trabalho (NUNAN, 1992). A análise se atém aos locais de produção discursiva e utiliza a técnica regrounding (SELIGER; SHOHAMY, 1990), caracterizada pela volta aos dados por uma segunda vez com vistas a comparar os resultados de uma segunda análise com os resultados da primeira, e, assim, buscar categorias, padrões ou aspectos comuns produzidos nas duas análises.

\section{5) Análise e discussão da (trans)formação inicial}

Durante as semanas iniciais do curso, foi possível perceber que o conceito de reflexão crítica estava sendo instaurado a partir dos relatos informais dos participantes e à medida que as discussões aconteciam. Foi verificada a novidade do conceito entre eles, os quais se abasteciam das teorias discutidas e indicadas pela ementa do curso para referenciar os exemplos, as práticas desenvolvidas, as experiências de ensinar durante a formação. Na última nota de campo, relatei, como pesquisador, o avanço dos participantes acerca dos conceitos e exemplificações sobre a reflexão crítica. Mais do que isso, o quanto eles estavam simpáticos à nova postura de reflexão crítica possivelmente a ser adotada em sua abordagem de ensinar além da língua:

[01] Hoje fiquei muito impressionado com a destreza de Denis e Penélope ao relacionar o momento crítico da experiência de ensino vivida por Samya nos pontos chaves da teoria de Hawkings e Norton (2009). Parece-me que os alunos estão muito simpáticos e envolvidos em relação à reflexão crítica. Falo isso porque Samya tem demonstrado que está praticando em sua escola alguns conceitos de reflexão crítica assimilados aqui. Estou aprendendo muito com os exemplos dela e de outros alunos.

(Encontro 3 - Nota de campo)

A partir dos relatos obtidos com a aplicação dos questionários no Encontro 10, também pude confirmar como esses alunos estavam lidando com os novos conceitos de ensinar além da língua na formação, discutidos durante as primeiras reuniões. Vejamos os excertos e, em seguida, os comentários. 
[02] [o conceito de ensino além da língua na formação] é algo muito novo para mim. É como se tudo que eu tivesse aprendido até aqui fosse por água abaixo. É uma nova visão que eu encaro como desafio, mas na realidade, ao mesmo tempo, é algo preocupante. Principalmente quando sabemos do nosso verdadeiro papel e do nosso verdadeiro poder de influência para o bem ou para o mal.

(Encontro 10 - Paola - Questionário socioeconômico)

[03] Acho tudo novo, porém muito importante. Porque hoje sei que minhas adoções ao estilo de ensinar estão sob fortes influências, inclusive de influências políticas, que antes nunca tinha me importado.

(Encontro 10 - Carlos - Questionário socioeconômico)

Os sentimentos positivos de Paola e de Carlos retratam a satisfação e, ao mesmo tempo, a preocupação com o desafio de ensinar além da língua. Esses participantes evidenciam que passaram a compreender a reflexão crítica como um novo conceito para suas aulas de línguas, sustentado por características políticas e discursivas. Paola, por exemplo, descreveu sobre a mudança de suas concepções pedagógicas e, ao mesmo tempo, alegou que a reflexão crítica na formação, conceito novo para ela, consistia em um desafio "obrigatório" de aplicação. Ela, ao longo do curso, esteve convicta sobre o poder de influência que professor exerce nas relações com seus alunos em sala de aula. Sobre tais aspectos, é importante mencionar, ainda, que Moita Lopes (2003) considera relevante a consciência sobre a dimensão política ocupada pelo professor, a qual inclui questões culturais, históricas, contextuais, identitárias etc. movimentando o processo de aprender línguas.

Já Carlos não se considera um professor crítico ou um professor que ensina além da língua, porém observa, assim como a participante Penélope em sua narrativa na sequência, que as novas concepções fluídas ao longo do curso equivalem ao fato de o professor se conscientizar e analisar suas próprias crenças e ações efetivadas ao ensinar. Essa característica de mudança das crenças é discutida por Barcelos (2004), que observa a importância de o professor revê-las e, quando necessário, ressignificar sua forma de ensinar. Veja o depoimento e as impressões de Penélope que, assim como os licenciandos anteriores, começou a se empoderar das leituras teóricas e discussões colaborativas produzidas no grupo.

[04] [O curso] Tem me movido fortemente. E depois que entendemos o que é [ensinar além da língua], começamos a rever todo tempo nossa prática. Só que com olhares muito mais amplos sobre os casos. Eu fico me perguntando sobre quantas vezes fui tecnicista. Ano passado, aprendi todos os métodos e metodologias de ensino de língua estrangeira nas aulas, e de nada vai adiantar se eu não conciliar as oportunidades que acontecem no meu dia-a-dia para refletir e discutir com meus alunos sobre elas. Isso também é língua! Porque isso faz parte da gente! Mas, antes, eu só preocupava com o vocabulário do livro e esquecia da realidade dos meus alunos.

(Encontro 10 - Penélope - Questionário socioeconômico) 
De modo geral, percebi que o curso implementado serviu como forma de provocação e, naturalmente, como forma de ressignificar crenças de muitos professores em (trans)formação. Através dos relatos 2, 3 e 4, foi possível verificar que o aparato teórico estudado e as discussões travadas ao longo das reuniões geraram interessantes momentos de reflexão crítica acerca da prática desses participantes, corroborando estudos que salientam sobre a ação de empoderamento produzida pela leitura (FREIRE, 2006).

No que tange à análise crítica de conteúdos dos livros didáticos, durante o encontro 11, as participantes Samya e Pénelope apresentaram em slides algumas inferências de ensino além da língua acerca de uma determinada unidade contida no recurso didático: "Por que estamos tão gordos?". Para facilitar a contextualização, a unidade do livro trazia uma concepção de que ser gordo era algo apenas caracterizado por maus hábitos e estilo de vida geralmente não saudáveis. Desse modo, as pessoas precisariam emagrecer correndo na esteira e as ilustrações dessa lição comparavam alguns estereótipos: a figura de uma pessoa gorda e sem disposição com a figura de uma pessoa magra e com vigor. Em meio às interações colaborativas e às negociações de significados suscitadas no grupo colaborativo, Samya, que já é professora, descreveu sua prática de ensino anterior em que usava o mesmo conteúdo proposto pelo livro didático e a confrontou com reflexões críticas:

[05]

Samya: eu passei por um momento muito difícil, triste, no ano passado [na escola em que trabalho]. A [Penélope] sabe bem disso, eu contei pra ela, porque essa unidade, ela apresenta algumas noções de protótipos, os desenhos mostram isso, vocês acabaram de ver, que a gente tem que ser magro, e que gordo, ser gordo, é sinal de doença. O vocabulário aprendido na lição é do must, você deve perder peso, deve! Obrigação! Só que tinha uma bendita de uma aluna lá, que era bem for-ti-nha.

Penélope: Gorda!

Samya: É! Gorda! E eu deixei ela muito decepcionada! Só que vocês sabem como é escola particular, a mãe dela foi lá e veio me dizer algo que, até então, eu não sabia: a menina gorda tomava re-mé-di-os, por causa de uma doença crônica que ela tinha. O remédio a fazia ficar inchada, gorda. Era um medicamento muito forte e o pior: eu não sabia disso! E eu lembro bem sobre o quanto os meninos a zoavam, e eu nunca fiz nada. Porque eu só tenho essa reflexão hoje!

(Encontro 11 - Gravação das interações em áudio)

Com base no relato de Samya, é interessante notar que a participante somente se atentou para o quanto suas próprias ações em sala de aula contribuíam para questionar os insumos do livro didático depois de conhecer a proposta de ensino além da língua e de se conscientizar sobre o papel do professor em sala de aula como modificador ou perpetuador de práticas já existentes. A esse respeito, Moita Lopes (2003, p. 46) observa que compreender esse e outros tipos de discursos presentes no ensino de ILE equivale a desconstruir e "colaborar na articulação de outros discursos/significados sobre a vida humana”. Como vimos, Samya passou a ter essa percepção crítica após os encontros do 
curso e ela percebeu que os insumos provenientes do livro didático configuravam uma transmissão discursiva muitas vezes sem problematização do que estava posto ao abstrair conceitos socioculturais importantes de discutir criticamente em aula de LE, tais como diferenças sociais, físicas, entre outras.

Na sequência, a narrativa multimídia de Denis descreve e, ao mesmo tempo, retrata sobre a experiência de ensino por ele vivenciada. Ele produziu esse texto embebido de seus sentimentos ocasionados pela participação no curso e, durante o encontro 12, leu-o em voz alta para todos os cursistas. Em sua opinião, o fato mais interessante de ele ter frequentado o curso de Reflexão Crítica consiste na sua transformação pessoal, como ele mesmo relata:

[06] Nunca vou me esquecer do dia em que levei frutas naturais para a sala de aula e o [professor formador] a me observar durante a aula prova de Estágio. A única coisa que sei é que se vivesse situação semelhante novamente, eu jamais faria igual. Início de março/ 2010. Estava em uma sala de alunos de primeiro ano do ensino médio, em uma tarde quente e agitada, em um recinto cheirando a hormônios. Ao apresentar o vocabulário sobre Fruits, um aluno me olha torto, uma aluna olha para a parede, alguém joga um aviãozinho de papel no quadro-negro, [o professor formador] também me olha como se quisesse me dizer: "está percebendo?", escuto murmúrios de "hummm, boiola"... Tudo fluía até eu pegar uma banana para exemplificar. Quando a pego e apresento o seu vocabulário, então ouço em bom tom: "Do you like this fruit, teacher?". Volto-me para a banana e observo a forma com que meus dedos a seguravam. Fiquei roxo, vermelho. Isso para não dizer rosa. Sim, eu tinha preconceito sobre mim mesmo. E talvez nunca ousasse escolher a cor rosa, porque ela poderia denunciar algo muito forte sobre mim que eu não quisesse ou não pudesse "enxergar". Respirei fundo. Talvez por isso! Continuei a exposição de vocabulário. Aquilo parecia me perseguir justo em um dia avaliativo. Outra vez, o mesmo aluno insiste ao perceber que não lhe respondi nada. Dessa vez, bem toante "Teacher, are you fruit?". Todos os seus colegas entenderam e riram. Eu também entendi muito bem o que ele queria me perguntar. E era a chance de aproveitar um novo vocabulário para ensiná-lo, porque fruit não poderia significar viado em inglês. É uma espécie de metáfora. Eu não fiz nada. Ignorei. E hoje me envergonho da postura ridícula que assumi perante todos. Porque hoje estou conhecendo o que é ser professor de línguas. Mesmo que precisasse de um planejamento antecipado, noções sobre diversidade poderiam ter sido apresentadas naquele espaço. E eu sei que alcançariam negros, gordos, gays e pobres naquela turma. No decorrer desses dias, eu percebo que tenho mudado. Eu jamais serei o mesmo. Mas também é importante para o trabalho que desejo realizar no futuro nesse sentido. Os alunos precisam entender sobre os problemas que circundam a vida social deles. Precisam sentir a dimensão das coisas. Nem sei se posso chamar de aulas as reuniões que temos dividido aqui, as experiências de formação, porque me fazem tão bem. Talvez seja por isso a má concepção que tenho de que aula é algo obrigatório. E elas deveriam ser prazerosas. Mas, para isso, elas devessem partir de algo dentro nós.

(Encontro 12 - Narrativa multimídia de Denis)

Podemos depreender que as aulas de reflexão crítica na formação evidenciando a perspectiva de ensino além da língua, através do contato colaborativo com participantes que se enquadravam no perfil de professores graduandos, concederam a oportunidade de voz a Denis. De forma espontânea, o participante fez um paralelo entre suas práticas anteriores, efetivadas sem o conhecimento dos conceitos instaurados, e suas práticas 
futuras, supostamente ativadas a partir dos novos conceitos assimilados. Dessa forma, podemos perceber que o curso modificou sua vida pessoal e, se não propiciou, pelo menos aguçou suas problematizações a respeito de questões relativas à sua própria aceitação dentro do grupo. Antes, ele acreditava que questões sobre sua orientação sexual no contexto de sala de aula podiam se passar por despercebidas e, de acordo com a sequência de seus depoimentos, passou a compreender a importância de problematizar esses e outros temas críticos durante as aulas, após frequentar o curso.

Em relação às sessões reflexivas realizadas durante um dos encontros, outro recorte a que faço referência diz respeito a um momento crítico ocorrido durante a aula ministrada por Paola na escola. Na sessão de visionamento, a participante conta que estava ministrando conteúdos quando se deparou com uma briga entre seus alunos. A sequência das ações do vídeo projetado mostra dois alunos do sexo masculino em luta corporal. Retirando os xingamentos e adaptando as falas a uma linguagem escrita compreensível, um dos meninos irritado diz: "Você devia tomar banho antes de vir para cá, você fede! E suas unhas são podres de sujeira. Unha preta! Vai para sua casa tomar banho. Vai comprar livro, porque nem livro você tem para estudar. Depois você vem!". Os colegas riem e, em coro, zombam do aluno humilde que estava na briga. Durante a rememoração da aula em vídeo, sobre o conflito entre os discentes, Paola reflete:

[07] Nessa hora, eu só separei os dois alunos que sentavam próximos [brigando], sentavam perto um do outro, eu só os mudei de lugar e adverti que se acontecesse aquilo de novo, eu chamaria o coordenador. Mas eu nem perguntei também se eles queriam sentar nos lugares que eu os coloquei, nem também perguntei porque eles brigaram, não problematizei a situação ridícula que aquele menino mais humilde sofreu! Mas eu sei quem ele é pobrezinho financeiramente, e [o aluno] que ofendeu ele tem mais condições financeiras do que ele, que eu também sei. Está vendo!? Antes eu não via essas coisas, essas questões de hierarquias sociais em sala de aula, porque, na realidade, eu nem sei se não via, viu?! Eu, no fundo, sei que elas não faziam parte do que hoje eu vejo. Quando esse vídeo rodou, eu vi o espaço macro figurado em sala de aula, o maior operando sobre o menor. Na hora! Eu me lembro de todas as leituras que a gente fez nos encontros. E hoje sei que isso pode e deve ser tratado em sala de aula como input. [...] Eu devia ter feito alguma coisa, só que eu não fiz! Eu acho que os esses adolescentes, todos assim, já estão passando da hora de começar a refletir sobre suas ações, e nós, como professores, devemos começar a praticar isso com eles! Eu sei que posso ser uma professora melhor, viu?! Com tudo que eu tenho visto hoje! A gente passa a entender mais [...] eu fico com remorso de não ter feito nada! [...] Eu sei do background daquele menino, ele é trabalhador, ele trabalha na oficina mecânica [de um conhecido] [...] De manhã ele vai ao colégio e depois ele trabalha a tarde toda lá na oficina. Ele é honesto, você tem que ver! Mas algo aconteceu para agir daquele jeito, viu?!

(Encontro 13 - Sessão reflexiva com Paola)

Paola, com o controle remoto na mão, pausou várias vezes nessa cena e trouxe à tona essas declarações. Grosso modo, elas servem para observarmos que os encontros proporcionados pelo curso implementado, de alguma forma, modificaram a maneira de Paola perceber os eventos críticos em sala de aula. Além disso, a participante deixa transparecer o seu desejo de mudanças, caso passe novamente por situações 
semelhantes. Na sequência de seus relatos, tenta buscar formas de como a ação poderia ter sido abordada. Algumas de suas reflexões críticas configuram o trabalho relevante com insumos em ILE provenientes de temas próximos à realidade daquele contexto (pobreza e desigualdade social), e ao fato de o professor desenvolver em interação com o aluno momentos de reflexão sobre suas próprias ações estudantis.

No penúltimo encontro, houve a apresentação de projetos de ensino para além da língua, elaborados no decorrer do curso de Reflexão Crítica pelas duplas de participantes. Paty e Paola desenvolveram um projeto curioso. As alunas planejaram a elaboração e produção de alguns materiais de insumo com nuances de reflexão crítica. Os materiais e apostilas confeccionadas seriam endereçados a uma escola pública. Antes da produção, a elaboração foi sustentada por meio de diagnósticos realizados após visitas ao contexto e levou em consideração a realidade e o gosto do alunado daquela turma de ensino médio visitada previamente. Os conteúdos versaram sobre questões críticas e discursivas não convencionais em relação às propostas convencionais do livro didático, calculando, assim, o impacto, por exemplo, que a figura de uma prostituta, ao trabalhar o tema Profissões, poderia causar nas discussões durante a aula de ILE.

A proposta de Carlos e Pink, por sua vez, dizia respeito à criação de um curso de reflexão crítica na formação que alcançasse professores de ILE da região envolvendo o contexto público estadual e municipal, a fim de instaurar o conceito de reflexão crítica. Esses participantes averiguaram a necessidade de estender esse curso a todos os professores de ILE da rede pública local. Na apresentação oral desse projeto, pude observar a influência que um professor formador pode estabelecer na propagação de mudanças mais significativas em relação a seus alunos, corroborando estudos que indicam esse tipo de característica (CONTRERAS, 2002; OLIVEIRA, 2013).

Samya e Penélope, por fim, não planejaram necessariamente um curso, todavia, se motivaram a desconstruir, sob o viés da crítica, as crenças de que não se aprende ILE em escolas públicas. Como Penélope trabalha como contrato temporário em uma escola pública estadual, as estudantes decidiram fazer um trabalho de conclusão de curso, mais especificamente uma pesquisa-ação com uma turma, conciliando a obrigatoriedade de produção de uma pesquisa no final da licenciatura. Pelas conversas informais que tivemos, os dados foram riquíssimos e os resultados finais foram mostrados a um grande número de professores de ILE da cidade como forma de um contradiscurso em relação àqueles já vigentes nesse sentido. As participantes se apoiaram nas teorias críticas de Pennycook (1999, 2004) e de Moita Lopes (2003) em relação às práticas discursivas operando o mundo atual e sua nova ordem, divulgadas e colaborativamente compartilhadas durante os encontros.

Fiz questão de mapear tais projetos, que se configuraram como produto do curso, a fim de que visualizássemos o impacto positivo da reflexão crítica instaurada nesses participantes ainda na graduação. Os projetos criaram oportunidades em que foi possível refletir criticamente sobre o ensino realizado em escolas da cidade e renderam, grosso modo, a prática da reflexão crítica ao diagnosticar e abarcar supostas práticas para lidar com determinados desafios escolares. Com isso, os cursistas estenderam a 
problematização do ensino além da língua à prática e a possibilidades - senão a necessidade - de mudança sobre o ensino que a todos eles era (im)posto.

Quanto às entrevistas semiestruturadas, selecionei fragmentos narrativos dos participantes que apontam para respostas bastante motivadoras de discussão neste estudo. Sobre a pergunta Qual foi o significado desse curso para você, os professores em formação relataram:

[08]

Samya: Eu mudei de todas as formas que vocês pensarem, eu passei a existir no mundo! E a minha sala passou a ser vista, pra mim, como um lugar onde eu tenho um dever social muito grande como professora de inglês.

Denis: Também acho isso [...] Eu acho que [ensinar além da língua] é, igual você tá falando, muito mais pesado que reflexivo! É como se "ser reflexivo" fosse algo com você mesmo! E ser reflexivo crítico é com você mesmo e com o mundo que tá ao seu redor! É perceber isso!

(Encontro 15 - Entrevista semiestruturada)

[09] Eu não sei por que nunca teve isso aqui [na graduação]! E olha que não devia ser só esse semestre! Devia ser no curso durante o curso todo, desde a hora que a gente entrasse aqui [na graduação], e nunca mais parar!

(Encontro 15 - Paola - Entrevista semiestruturada)

[10] Parece que esse curso faz a gente ficar mais atento com o que pode acontecer sempre quando eu digo algo lá pros meus alunos.

(Encontro 15 - Paty - Entrevista semiestruturada)

Como vimos, os relatos anteriores mostram a importância de a reflexão crítica adentrar os muros das universidades na formação graduação. Segundo os participantes, são conceitos que mudaram suas vidas no sentido de lidar política e discursivamente com a práxis diária de ensinar LE. Samya e Denis concordam que a reflexão crítica ou ensino além da língua consiste e se propaga na relação social e na discussão e elaboração de possibilidades, concepção essa que reitera os estudos de Pennycook (1999) e de Urzeda-Freitas e Pessoa (2014). O mais interessante é notar que os depoimentos alcançaram a noção de que refletir criticamente não significa criar modelos prontos para as situações e, sim, possuir um repertório de problematizações que indicam causas e consequências imprevistas, dignas sempre de análise e de colaboração para projeções e investidas futuras.

\section{Considerações finais}

O curso surtiu o efeito esperado, o de instigar o aluno a questionar seus fazeres pedagógicos de forma crítica e alinhada à base sociocultural e contextual de ensino e o de ensinar além da língua. Particularmente, durante alguns anos de trabalho com formação de professores na graduação, foi a primeira vez que vi, na prática, a difusão de conceitos reflexivos e críticos tão bem mapeados e discutidos por alunos 
interessados em mudanças. Através das interações, os discursos situados dos participantes revelaram que ensinar além da língua valoriza a identificação dos fatos e o questionamento de sua veracidade à luz do bom senso que simboliza a relatividade. Isso porque sabemos que as problematizações sobre as questões pedagógicas levantadas devem ser ponderadas à luz dos fatores socioculturais e contextuais, desprezando a alusão ignóbil a modelos únicos e encaixáveis. A reflexão crítica na formação de professores não é uma fórmula, mas pode ser concebida como uma solução dentro de todos os imprevistos que evocam a ação política e discursiva do docente nas negociações de significado em sala de aula. Para isso, cada professor encontra a sua própria solução, partindo de seu contexto, do confronto entre as teorizações vivenciadas e a prática, das discussões colaborativas e compartilhadas. O fato é que, no império das relações sociais de poder, é preciso reflexão crítica sempre.

Pennycook (2004) afirma que é pertinente considerar que, em sala de aula, temos alunos múltiplos, contraditórios e construídos dentro dos diferentes discursos, ao mesmo tempo em que, reiterando Foucault (1993), é preciso perceber esses indivíduos sociais transitando nas relações de poder existentes dentro do cenário de sala de aula. Por essa razão, não podemos desconsiderar aspectos políticos e culturais da aprendizagem de uma LE, uma vez que as negociações que constroem significados em uma aula se dão por meio da interação social entre indivíduos heterogêneos. A nossa tarefa docente é delinear os discursos que constroem regimes de verdade e regulam os estudantes nesses espaços educacionais, o que nem sempre é tão fácil. Todavia, trata-se de um trabalho relevante com vistas a observar que há muito céu por detrás da língua dos seres humanos: há cultura, há discursos, há intenções. Então, pensando na flexibilidade existente entre o fluxo do discurso e as identidades em construção na hora de aprender uma nova língua, cabe a nós, professores de línguas e agentes políticos, em geral, construir discursos alternativos que colaborem na luta contra a hegemonia e a favor da diversidade e da igualdade de oportunidades.

\section{Referências}

AUSTIN, John Langshaw. How to do things with words. New York: Oxford University Press, 1965.

BAKHTIN, Mikhail Mikhailovich. Marxismo e filosofia da linguagem. São Paulo: Editora Hucitec, 2004.

BARCELOS, Ana Maria Ferreira. Crenças sobre aprendizagem e ensino de línguas: o que todo professor de línguas deveria saber. In: CAMPOS, Maria Cristina Pimentel; GOMES, Maria Carmen Aires. (Org.). Interações dialógicas: linguagem e literatura na sociedade contemporânea. Viçosa: Editora UFV, 2004. p. 15-40.

BORELLI, Julma Dalva Vilarinho Pereira; PESSOA, Rosane Rocha. Linguística aplicada e formação de professores: convergências da atuação crítica. In: PESSOA, Rosane Rocha; BORELLI, Julma Dalva Vilarinho Pereira. Reflexão e crítica na formação de professores de língua estrangeira. Goiânia: Editora UFG, 2011. p.15-30. 
CONTRERAS, José. A autonomia de professores. São Paulo: Cortez, 2002.

FAIRCLOUGH, Norman. Teoria social do discurso. In: Discurso e mudança social. Tradução de Izabel Magalhães. Brasília: Editora UnB, 2001. p. 89-131.

FOUCAULT, Michel. Microfísica do Poder. Rio de Janeiro: Graal, 1993.

FREIRE, Paulo. Pedagogia do oprimido. Rio de Janeiro: Paz e Terra, 2006.

GIL, Gloria; VIEIRA-ABRAHÃO, Maria Helena. (Org.). Educação de professores de línguas: os desafios do formador. Campinas: Pontes Editores, 2008.

GIMENEZ, Telma Nunes. Tornando-se professores de inglês: experiências de formação inicial em um curso de Letras. In: VIEIRA-ABRAHÃO, Maria Helena. (Org.). Prática de ensino de língua estrangeira: experiências e reflexões. Campinas: Pontes, 2004. p. 171-187.

HAWKINGS, Margaret; NORTON, Bonny. Critical language teacher education. In: BURNS, Anne.; RICHARDS, Jack. (Eds.). Cambridge guide to second language teacher education. Cambridge: CUP, 2009. p. 30-39.

JOHNSON, K. E. Second language teacher education: a sociocultural perspective. New York: Routledge, 2009.

LIBERALI, Fernanda Coelho. Formação crítica de educadores: questões fundamentais. Campinas: Pontes Editores, 2010.

MATEUS, Elaine. Para além do espelho: reflexão como produção de novas práticas sociais. In: BARROS, Solange Maria; ASSIS-PETERSON, Ana Antônia de. Formação crítica de professores de línguas: desejos e possibilidades. São Carlos: Pedro e João Editores, 2010. p. 27-40.

MATEUS, Elaine; OLIVEIRA, Nilceia Bueno de. (Org.). Estudos críticos da linguagem e formação de professores/as de línguas: contribuições teóricometodológicas. Campinas: Pontes Editores, 2014.

MOITA LOPES, Luiz Paulo da. A nova ordem mundial, os parâmetros curriculares nacionais e o ensino de inglês no Brasil: a base intelectual para uma ação política. In: BARBARA, Leila; RAMOS, Rosinda de Castro Guerra. (Org.) Reflexões e ações no ensino-aprendizagem de línguas. São Paulo: Mercado das Letras, 2003. p. 29-57.

Linguística aplicada e vida contemporânea: problematização dos construtos que têm orientado a pesquisa. In:

Paulo: Parábola, 2006. p. 85-107. (Org.) Por uma lingüística indisciplinar.São

NUNAN, David. Research methods in language learning. Cambridge: Cambridge University Press, 1992.

OLIVEIRA, Hélvio Frank. Esculpindo a profissão professor: experiências, emoções e cognições na construção das identidades docentes de licenciandos em Letras. $302 \mathrm{f}$. Tese (Doutorado em Letras e Linguística) - Universidade Federal de Goiás, Goiânia, 2013. 
PENNYCOOK, Alastair. Introduction: critical approaches to TESOL. TESOL Quartely, v. 33, n. 3, p. 329-348, 1999.

Critical moments in a TESOL praxicum. In: NORTON, Bonny; TOOHEY, Kelleen. (Ed.) Critical pedagogies and language learning. Cambridge: CUP, 2004.p. 327-345.

PIMENTA, Selma Garrido. Pesquisa-ação crítico colaborativa: construindo seu significado a partir de experiências de formação e na atuação docente. In: GHEDIN, Evandro; FRANCO, Maria Amélia Santana.(Org.). Pesquisa em educação: alternativas investigativas com objetos complexos. São Paulo: Loyola, 2006, p. 25-64.

RAJAGOPALAN, Kanavilil. ELT classroom as an arena for identity clashes. In: GRIGOLETTO, Marisa; CARMAGNANI, Anna Maria Grammatico. (Eds.). English as a foreign language: identity, practices, and textuality. São Paulo: Humanitas, 2001.

SANTOS, Milton. Por uma outra globalização. Rio de Janeiro: Record, 2000.

SAPIR, Edward. Language. In: Culture, language and personality. Berkely: University of California Press, 1949.

SELIGER, Herbert W.; SHOHAMY, Elana. Second language research methods. Oxford: Oxford University Press, 1990.

URZEDA-FREITAS, Marco Túlio; PESSOA, Rosane Rocha. Discursos de identidades, ensino crítico de línguas e mudança social: análise de uma experiência localizada. In: MATEUS, Elaine; OLIVEIRA, Nilceia Bueno de. (Org.). Estudos críticos da linguagem e formação de professores/as de línguas: contribuições teóricometodológicas. Campinas: Pontes Editores, 2014. p. 365-396.

VYGOTSKY, Lev Semenovitch. A formação social da mente: o desenvolvimento dos processos psicológicos superiores. São Paulo: Martins Fontes, 1998. 